\title{
Sickness absence and early retirement on health grounds in the construction industry in Ireland
}

\author{
Harold Brenner, William Ahern
}

\begin{abstract}
Objective-To establish a detailed pattern of the nature and extent of illnesses and injuries among construction workers in Ireland which cause temporary absence from work, and to identify diseases and disabilities which lead to premature retirement from the industry on health grounds.
\end{abstract}

Methods-The population base for the study consisted of construction workers who were members of the Construction Federation operatives pension and sick pay scheme. Records of sickness absence since 1981, stored on computer disks, and records of early retirement on health grounds since 1972, stored on microfiche film, were examined. Pertinent data were extracted and transferred to a database; after cleaning and the exclusion of unvalidated data, records of 28792 absences and 3098 records of early retirement were available for analysis. Data were analysed with Access 97 and Epi Info.

Results-Over the period of the study the mean annual absences were $7.8 / 100$ workers. Three quarters of absences were among younger workers; however, the rate of absence increased with age, as did the mean duration of absence. Injury was the most frequent reason for absence, followed by infectious disease, then musculoskeletal disorders. The mean annual rate of early retirement on health grounds was $5.3 / 1000$ workers. The median age at retirement was 58 years. Cardiovascular disease and musculoskeletal disorders each accounted for nearly one third of the conditions leading to permanent disability on the grounds of which early retirement was granted. During the period of the study, over 677000 working days were lost due to sickness absence, and over 24000 potential years of working lives were lost due to early retirement on health grounds. Conclusions-The study has shown patterns of sickness absence and early retirement on health grounds in the Irish construction industry which will contribute to the further development of health promotion strategies for construction workers.

(Occup Environ Med 2000;57:615-620)

Keywords: construction industry; sickness absence; early retirement

The range of health disorders among industrial workers which result in absence from work is well documented, ${ }^{2}$ and it is recognised that construction workers are at greater risk of developing certain health disorders than are the general population and workers in other industries ${ }^{3-5}$; however, patterns of illness and injury giving rise to sick leave or early retirement on health grounds in the Irish construction industry are not known.

Conditions which contribute most to absenteeism are back injuries, fractures, other injuries due to hits or falls, influenza and upper respiratory infections, and arthritis ${ }^{1}$; when occupations are ranked according to their contribution to specific diseases, unskilled construction workers rank consistently high in most lists of diseases. ${ }^{6}$ In the United States, a review of alcoholism and occupations showed a high prevalence of alcohol dependence and misuse in the construction industry; more than one in four construction labourers and one in five skilled construction trades workers had a diagnosis related to alcohol misuse. ${ }^{7}$ In Germany, a study of the health of workers aged 40-64 years in the construction industry showed that construction workers, compared with white collar workers, had higher prevalences of hearing deficiencies, musculoskeletal abnormalities, high body mass index, and signs of obstructive lung disease; in a 5 year follow up of the study population, compared with white collar workers, there was a marked increased rate of disability among construction workers leading to men leaving the labour market. The authors concluded that their study showed both the need and possibilities for further health promotion in workers employed in the construction industry, targeting both work related conditions and personal lifestyle factors. ${ }^{8}$ A review of sickness and absence from work in the construction industry due to skin diseases showed that occupational dermatoses are the most important causes; it was noted that despite extensive skin problems, workers sometimes continue to work without consulting a physician. ${ }^{9}$ In the United Kingdom, levels of sickness absence in the construction industry, based on labour force surveys, are very high. ${ }^{2}$ In a self reported survey of work related illnesses over the previous years, the construction industry in the United Kingdom had the second highest relative risk of work related illnesses, second only to the coal mining industry; significantly increased relative risks of lower respiratory disorders, back disorders, and trauma were found in the construction industry. Interestingly, in nearly one half of the cases reported in this survey, the people took no sickness absence on account of their work related illness. ${ }^{2}$

As well as for morbidity, the pattern of mortality among construction workers compares 
unfavourably with that in other occupations and in the general population. ${ }^{10-12}$ Specifically there is a disproportionate share of occupational fatalities in the construction industry. ${ }^{13}$

A cross sectional survey in six organisations in the United Kingdom of retirement on grounds of ill health ${ }^{14}$ showed rates of retirement due to ill health varying from 2 to $25 / 1000$ contributing members in the period 1994-5. There was a more than 10-fold variation in rates of retirement between organisations, two of which were predominantly of manual workers; wide variations in rates were also found within two organisations. The most common reasons for retirement were musculoskeletal problems and minor mental illness. In a cohort study of construction workers aged $40-49$, the effect of smoking on early retirement due to permanent disability was assessed; the relative rate for permanent disability was 1.3 for current smokers compared with never-smokers. ${ }^{15}$

The objective of the study was to establish a detailed pattern of the nature and extent of illnesses and injuries among construction workers in Ireland which cause temporary absence from work, and to identify diseases and disabilities which lead to premature retirement from the industry on health grounds.

\section{Methods}

The population base for the absence part of the study consisted of construction workers who were members of the Construction Federation operatives pension and sick pay scheme, and thus were eligible to receive benefits, between January 1981 and August 1996. The population base for the early retirement part of the study consisted of eligible workers between January 1972 and June 1996. Data relating to absences from work due to illness in the industry are stored on computer disks in various formats. Pertinent data were extracted from these and transferred to a modern data base (Access 97) in a format amenable to analysis. Medical diagnoses, available since 1984 on general practitioner (GP) certifications, had been entered by administrative staff on the disks in textual form; invariably only one diagnosis was given by the GP. A computer programme was devised to code these diagnoses in numerical form, and these were allocated to broad morbidity groups, compatible with ICD-9 classification, by one of us (HB). Data relative to the early retirement part of the study are stored on microfiche film; pertinent information was extracted manually and entered into a database by the same author. Where more than one diagnosis was given as the basis for early retirement, the one most likely to be the main cause was selected.

Data which could not be validated were excluded. There remained data relating to 28792 records of absences from work and to 3098 records of early retirement. Data were analysed with Epi Info 6.04b and Access 97.
Table 1 Annual age specific rates of absence (per 100 workers)

\begin{tabular}{cccccc}
\hline \multicolumn{5}{c}{ Age specific rates } \\
Year & $20-29 y$ & $30-39 y$ & $40-49 y$ & $50-59 y$ & $60-64 y$ \\
\hline & & & & & \\
1981 & 8.4 & 9.0 & 8.9 & 10.1 & 12.4 \\
1982 & 12.9 & 14.1 & 14.9 & 15.4 & 18.0 \\
1983 & 8.8 & 10.3 & 11.2 & 12.1 & 15.1 \\
1984 & 8.3 & 9.5 & 10.6 & 13.0 & 15.4 \\
1985 & 7.6 & 9.2 & 10.4 & 13.0 & 14.2 \\
1986 & 6.7 & 5.6 & 8.5 & 12.2 & 15.8 \\
1987 & 5.7 & 5.9 & 6.1 & 9.4 & 9.7 \\
1988 & 4.6 & 4.7 & 6.3 & 6.8 & 9.0 \\
1989 & 4.3 & 4.9 & 5.4 & 7.3 & 11.6 \\
1990 & 5.1 & 4.8 & 6.0 & 8.8 & 12.9 \\
1991 & 5.7 & 6.9 & 8.2 & 10.7 & 14.3 \\
1992 & 4.9 & 6.3 & 6.8 & 9.4 & 13.6 \\
1993 & 5.1 & 6.5 & 8.4 & 11.0 & 17.0 \\
1994 & 4.8 & 5.5 & 6.8 & 8.5 & 11.9 \\
1995 & 5.5 & 6.4 & 7.6 & 9.5 & 14.5 \\
1996 & 4.5 & 5.8 & 5.7 & 7.7 & 13.3 \\
\hline
\end{tabular}

\section{Results}

ABSENCES FROM WORK

The number of eligible workers for each year varied between 33400 and 17300 with an annual mean of 22400 . The workers, over $99 \%$ male, were aged 18-64 years. The age distribution was almost identical for each year of the study period; $0.5 \%$ under the age of 20 , $32 \%$ aged $20-29,30 \%$ aged $30-39,21 \%$ aged $40-49,13 \%$ aged $50-59$ and $3.5 \%$ aged $60-64$.

An absence from work due to illness was recognised if it entailed more than 3 working days. There were 28792 such absences recorded over the period of the study, during which time 10589 individual workers were absent on one occasion only; 6172 workers were involved in more than one absence, an average of 2.9 absences for each of these. Of the workers involved in multiple absences, 57\% were absent on two occasions and just under $1 \%$ absent on 10 or more occasions; in the extreme case, the worker was absent on 26 occasions over a 15 year period.

The mean age at time of absence was 38.7 years; the median age was 37 years; reflecting the larger proportion of younger workers in the study population, $78 \%$ of absences were among younger workers (age below 50) and 22\% among older workers (age 50-64).

Figure 1 shows the number of absences as percentages of the population for each year, the rate for 1996 was calculated on an extrapolation for the year of the number of absences in the first 8 months. The annual mean absences were 7.8/100 workers. When standardised for age with the 1987 population as standard, because of the remarkably similar age distribution of workers in each year, the standardised rates were virtually the same as the crude rates shown in figure 1 . The rate of absence varied considerably from year to year, and there is a strong positive correlation (Pearson $r=0.8$, $\mathrm{p}=0.0005)$ between these rates and the corresponding populations for each year. Table 1 shows, for each year of the study, the age specific rates of absence, again the rates for 1996 were extrapolated from the data for the first 8 months of the year; the rate of absence rising with age is clearly illustrated.

For the purpose of this analysis, the number of working days involved in each absence is 


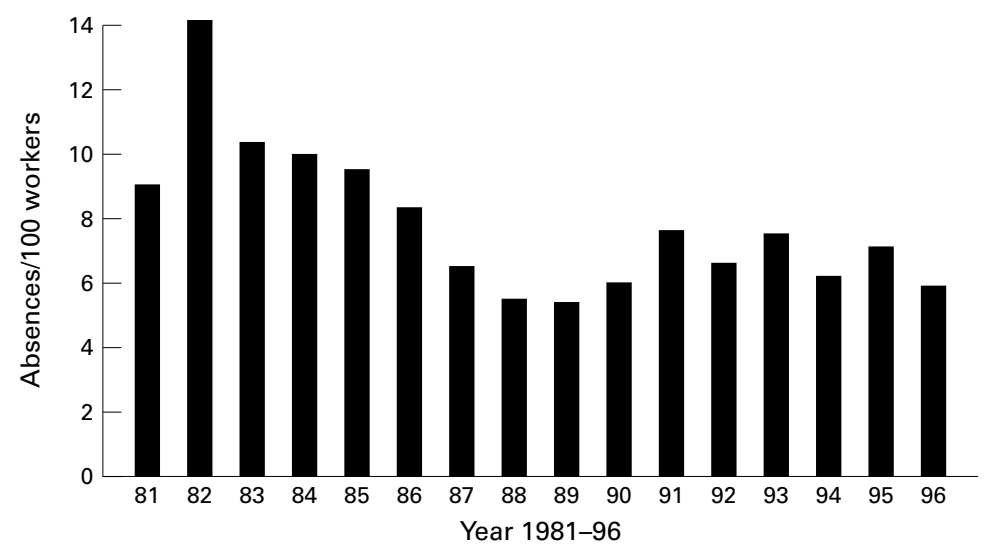

Figure 1 Rates of absence from work 1981-96.

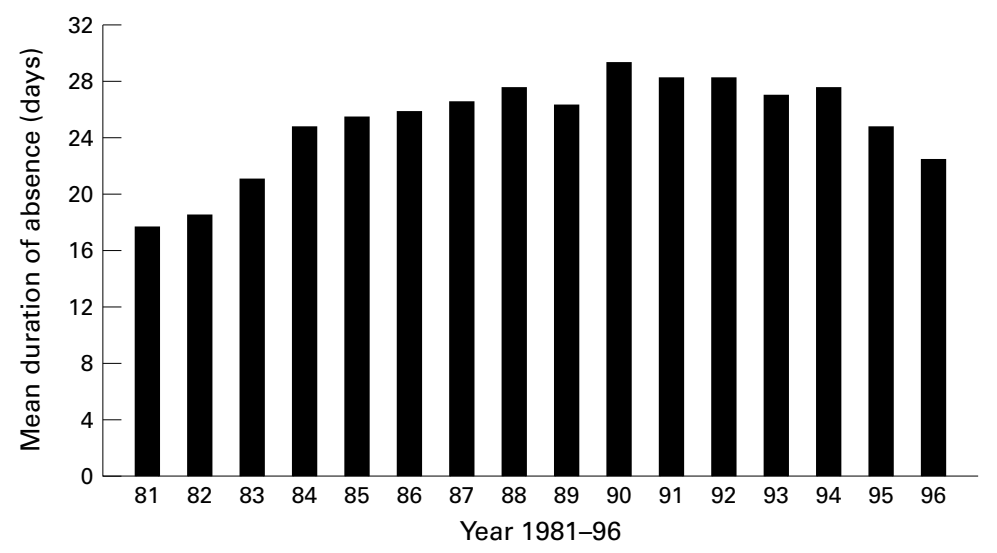

Figure 2 Annual mean duration of absence 1981-96.

Table 2 Percentage distribution of main diagnostic categories, and categories by age at time of absence

\begin{tabular}{lrrrrrrr}
\hline \multicolumn{7}{c}{ Age $(y)$} & \\
\cline { 3 - 6 } Diagnostic category & $\%$ & $20-29$ & $30-39$ & $40-49$ & $50-59$ & $60-64$ & Total \\
\hline Injury & 30.2 & 1670 & 1410 & 935 & 576 & 143 & 4734 \\
Infectious disease & 25.4 & 1028 & 1151 & 890 & 674 & 238 & 3981 \\
Musculoskeletal disorder & 13.1 & 362 & 593 & 569 & 406 & 127 & 2057 \\
Bronchitis, emphysema, asthma & 4.4 & 117 & 161 & 163 & 172 & 72 & 685 \\
Surgical procedure & 4.2 & 154 & 187 & 135 & 121 & 54 & 651 \\
Gastrointestinal disease & 3.7 & 111 & 182 & 136 & 115 & 30 & 574 \\
Cardiovascular disease & 3.6 & 24 & 62 & 167 & 224 & 92 & 569 \\
Mental disorders & 1.8 & 36 & 88 & 93 & 49 & 10 & 276 \\
Investigation & 0.9 & 23 & 44 & 30 & 48 & 9 & 154 \\
Neurological disease & 0.8 & 17 & 35 & 30 & 32 & 13 & 127 \\
Cancer & 0.1 & 2 & 2 & 6 & 2 & 4 & 16 \\
Other & 11.8 & 399 & 488 & 493 & 354 & 124 & 1858 \\
All & 100 & 3943 & 4403 & 3647 & 2773 & 916 & 15682 \\
\hline
\end{tabular}

used as the duration of absence. Overall the mean duration of absence was 23.5 days; the median duration was 17 days. The mean duration of absence for each year is shown in figure 2; the mean for 1996 was extrapolated from data of the first 8 months of the year. The mean duration of absence increased linearly with age: $19.5,22.8,25.6,27.4$, and 29 days in the 20-29, 30-39, 40-49, 50-59, and 60-64 year age groups, respectively. During the period of the study the number of days absence due to illness totalled 677440 , an annual mean of 42340 days. Recognising that these figures do not include the numbers of days where absences were less than 4 days duration, and using 230 working days as denominator, the annual percentage working days lost through sickness absence was calculated; the rates varied from $0.6 \%-1.1 \%$, the overall rate over the study period was $0.8 \%$.

Reasons for sickness absence were available for analysis in 15682 cases. In the balance of cases, no medical certificate was on file, no specific diagnosis was given on the certificate, or the diagnosis was illegible. A potential bias arose from the fact that in only $54 \%$ of absences was a diagnosis available for analysis. However, there is no reason to think that there are any demographic or health related differences between the population of workers who were absent for whom no diagnoses were available, and the population for whom diagnoses were available; any bias would be negligible.

Sickness absence may be defined as absence from work which employees attribute to sickness or injury and which the employer accepts as such; within this definition, sickness of other family members may be included as a reason for employee absence. However, available information suggests that all diagnoses in this study referred to employees. It was not possible to identify work related sickness or injury, nor was it a purpose of the study; data on occupational injury and occupational disease in the building and construction industry are available in publications of the Irish Central Statistics Office. Table 2 indicates the percentage distribution of the main diagnostic categories of sickness reported in the medical certificates that were available for analysis, and the categories grouped by age at the time of absence.

Injury was the most frequent reason for absence in the period under study, comprising $30 \%$ of all reasons. Further analysis showed that $56 \%$ of all injuries were to the arms and legs, $21 \%$ were back injuries, $9 \%$ were head and neck injuries, and $3 \%$ were multiple injuries. Taking the age structure into account, there were $12 \%$ more injuries in younger workers (under the age of 40 years) than in older workers.

Infectious disease $(25 \%)$ was the second commonest reason for absence. Influenza and upper respiratory tract infections in equal numbers comprised $48 \%$ of this category with chest infections accounting for $17 \%$. Unspecified viral infection was given as the reason in $25 \%$ of cases and gastroenteritis in $8 \%$ of cases. There were a few cases of meningitis (15) and tuberculosis (three).

Musculoskeletal disorders accounted for $13 \%$ of absences. Back pain or back ache was the reason in $60 \%$ of cases, arthritis in $14 \%$, vertebral disc disease in $13 \%$, inguinal hernia in $6 \%$, and there were smaller percentages of fibrositis, gout, and bursitis. Allowing for the age structure, vertebral disc disease was commonest in the 40-49 year age group.

Chronic respiratory diseases accounted for $4.4 \%$ of absences. These were variously described in the medical certificates as chronic bronchitis, bronchitis and emphysema, obstructive airway disease, and asthma. Taking the age structure into consideration, chronic 
Table 3 Total and mean working days lost due to absences attributed to each diagnostic category

\begin{tabular}{lcllrl}
\hline Diagnostic category & Days lost & $\begin{array}{l}\text { Mean } \\
\text { days }\end{array}$ & Diagnostic category & Days lost & $\begin{array}{l}\text { Mean } \\
\text { days }\end{array}$ \\
\hline Infectious disease & 67194 & 16.9 & Neurological disease & 3544 & 27.9 \\
Cardiovascular disease & 22406 & 39.4 & Mental disorder & 8939 & 32.4 \\
Cancer & 590 & 36.9 & Injury & 135660 & 28.7 \\
Bronchitis, emphysema, asthma & 15481 & 22.6 & Surgical procedure & 20377 & 31.3 \\
Musculoskeletal disorder & 58917 & 28.7 & Investigation & 4920 & 31.9 \\
Gastrointestinal disease & 17687 & 30.8 & Other & 49347 & 26.6 \\
\hline
\end{tabular}

Table 4 Diagnostic categories of permanent disabilities

\begin{tabular}{llrlll}
\hline Diagnostic category & \multicolumn{1}{l}{$n$} & \multicolumn{1}{c}{$\%$} & Diagnostic category & $n$ & $\%$ \\
\hline Cardiovascular disease & 954 & 30.8 & Skin disease & 41 & 1.3 \\
Musculoskeletal disorder & 928 & 30.0 & Endocrine disorder & 37 & 1.2 \\
Bronchitis, emphysema, asthma & 415 & 13.4 & Tuberculosis & 16 & 0.5 \\
Injury & 246 & 7.9 & Pulmonary fibrosis & 15 & 0.5 \\
Psychiatric disorder & 115 & 3.7 & Urinary tract disease & 14 & 0.5 \\
Neurological disease & 109 & 3.5 & Liver disease & 10 & 0.3 \\
Cancer & 78 & 2.5 & Other & 64 & 2.1 \\
Gastrointestinal disorder & 56 & 1.8 & All & 3098 & 100 \\
\hline
\end{tabular}

respiratory disease was much commoner in those over the age of 49 than in younger workers.

Cardiovascular disease accounted for 3.6\% of absences. Hypertension was the commonest cause in this category (27\%) followed by acute myocardial infarction $(21 \%)$. Vein disorders were reported in $14 \%$ of cases, myocardial ischaemia in $10 \%$, cardiac surgery in $5 \%$, and stroke in 3\% of cases.

Gastrointestinal disorders was reported in $3.7 \%$ of absences. By far the commonest condition was gastric or duodenal ulcer (62\%). Appendicitis accounted for $10 \%$ of cases, inflammatory bowel disease for $6 \%$, haemorrhoids for $6 \%$, and gall bladder disease for $4 \%$ of cases.

Mental disorders were responsible for $1.8 \%$ of absences; depression was the commonest diagnosis followed by anxiety neurosis. Stress and stress related illness (included in the "other" category of table 2) were reported as the reason for absence in 26 cases.

Neurological disease accounted for $0.8 \%$ of absences. Vertigo was reported as the cause in $60 \%$ of these. There were a few cases of facial palsy, neuritis, and epilepsy.

Cancer was reported in 16 cases $(0.1 \%)$ of absences. There were two cases of stomach cancer, three of limb cancer, and one each of cancer of the larynx, lung, brain, prostate, and testicle. Cancer type was unspecified in six cases.

Surgical procedures accounted for $4 \%$ of all reasons for absence. The commonest operative site was inguinal hernia $(20 \%)$ followed in order by limbs, eye, ear, nose and throat, varicose veins, appendix, abdomen (other than appendix), hip, and vertebral disc.

In the "other" category, which accounted for $12 \%$ of absences, pain (chest, abdominal, sciatic, and other) was given in 643 cases as the reason for absence, eye, ear, nose and throat disease was given in 262 cases, and urinary tract disease in 198 cases.

The number of working days lost relative to each of the main diagnostic categories was examined. Table 3 shows the total and mean days lost due to absence attributed to each diagnostic category. By far, the greatest number of working days lost was because of injury, twice as many as for infectious disease, the cause of the next highest number of days lost. Although cardiovascular disease was only fourth highest in terms of total number of days lost, it ranked highest in mean days lost; cancer was ranked second in mean days lost despite the comparatively low total number of days lost.

EARLY RETIREMENT ON HEALTH GROUNDS

Records of all 3098 construction workers granted early retirement on health grounds from 1972 to mid-1996 were available for analysis. The annual population for this part of the study also varied between 33400 and 17300 , but with an annual mean of 22300 .

The rate of retirements granted on health grounds in each year of the period of the study was calculated. The rates (again, age adjusted rates were similar to the crude rates) varied from 0.92 to $14.0 / 1000$ workers. A quadratic pattern in the yearly rates of retirement was noted with the highest rates, varying from 9.18 to 14.0 , from 1983 to 1988 . The mean annual rate of retirement was 5.3/1000 workers. The age of workers at the time of retirement was examined; as would be expected, most early retirements on health grounds occurred in the later years of working life ( $43 \%$ were at the age of 60 years and over), although $8 \%$ were of workers under the age of 45 years. The mean retirement age was 56.2 years, the median 58 years, the interquartile range $52-62$ years and the mode 63 years.

Early retirement on health grounds from the industry is based on certification of permanent disability by an independent occupational physician. The medical diagnoses extracted from the certificates were categorised and are shown in table 4 . Disability based on a diagnosis of cardiovascular disease accounted for $31 \%$ of retirements of which the greatest proportion $(56 \%)$ was coronary heart disease; hypertension accounted for $16 \%$ and stroke for $15 \%$ of this category. Musculoskeletal disorders comprised $30 \%$ of diagnoses of which all forms of arthritis accounted for $70 \%$ and degenerative disc disease for $20 \%$. Chronic respiratory disease accounted for $14 \%$ of diagnostic categories which included 11 cases of asbestosis and two cases of silicosis. Injury formed 8\% of the diagnostic categories of which injuries to the limbs and back contributed $63 \%$. The 78 cases of cancer included cancer of the lung and larynx (29), colon (11), brain (8), skin (7), urinary tract (6) and prostate (4). The relatively small category of endocrine disorders included 28 cases of diabetes mellitus.

Although the specific occupations of the workers granted early retirement were established in all but 27 cases, there were no reliable data on numbers employed in each occupation in the industry; an attempt to compare occupational risk of permanent disability meaningfully with proportionate morbidity 
Table 5 Potential years of working lives lost in each occupation (PYWLL), number of retirees $(n)$, and percentage of retirees under the age of $50(\%<50)$

\begin{tabular}{lrrrllllr}
\hline Occupation & PYWLL & $n$ & $\%<50$ & Occupation & PYWLL & $n$ & $\%<50$ \\
\hline Bricklayer & 712 & 85 & 20.0 & Manager & 210 & 19 & 21.1 \\
Carpenter & 2943 & 430 & 12.6 & Painter or decorator & 951 & 137 & 13.9 \\
Craftsperson & 11 & 2 & 0 & Plasterer & 769 & 116 & 9.5 \\
Clerk & 53 & 13 & 0 & Plumber & 327 & 45 & 17.8 \\
Driver & 2106 & 257 & 19.8 & Site manager & 631 & 94 & 12.8 \\
Electrician & 479 & 43 & 34.9 & Stone cutter & 226 & 44 & 4.5 \\
Fitter & 639 & 71 & 23.9 & Steelworker & 443 & 57 & 15.8 \\
Floor layer & 79 & 8 & 37.5 & Sheet metal worker & 284 & 19 & 42.1 \\
Glazier & 210 & 25 & 20.0 & Welder & 366 & 45 & 20.0 \\
General operative & 12767 & 1561 & 17.9 & Unknown & 222 & 27 & 55.6 \\
& & & & & & &
\end{tabular}

ratios failed because of relatively few cases in some categories.

During the period of the study, a potential 24428 years of working lives were lost due to premature retirement from the industry on health grounds, an annual mean potential loss of 977 years. Table 5 indicates, for each occupation, the potential years of working lives lost, the number of retirees, and the percentage of retirees under the age of 50 years. Occupations in which workers under the age of 50 years formed a high proportion of those retiring on health grounds were sheet metal workers $(42.1 \%)$, floor layers $(37.5 \%)$, and electricians $(34.9 \%)$.

\section{Discussion}

The study was undertaken by the Construction Employees Health Trust to develop a database which, together with lifestyle and other parameters of health obtained in screening and surveys, will provide information that will both contribute to the formation of a strategic health promotion policy for the construction industry in Ireland and provide focus and direction to the current workplace health promotion activities of the Trust. The World Health Organisation states that disease prevention and health protection services in the workplace are essential components of an integrated approach to improving the health of workers. ${ }^{16}$ This concept is incorporated into the development of a framework for the creation of healthy workplaces in Northern Ireland ${ }^{17}$ in which prevention of work related disease and injury and the promotion of positive healthy lifestyle behaviours are key elements. Although a meta-analysis of trials of multiple risk factor interventions for preventing coronary heart disease showed that standard health education methods have limited use in reducing risk factors in the general population, ${ }^{18}$ other studies have shown that workplace health promotion has been successful in reducing days of disability ${ }^{19}$ and in modifying dietary habits. ${ }^{20}$

The present study did not include all workers in the industry, only those whose records were available as a consequence of membership of the pension and sick pay scheme. It is estimated at this time that only two thirds of construction workers in Ireland eligible for membership of the scheme are in fact members.

The annual rates of absences from work varied from 14.1 to $5.4 / 100$ workers. The rates over the period of the study showed a strong positive correlation with the populations in corresponding years; the middle period of the study were recession years in the industry, and a possible explanation for the correlation is that workers were reluctant to take sick leave for minor illnesses in recession years. Although three quarters of absences were among workers under the age of 50 years, as in most industries $^{21}$ the rate of absence was higher in the older age groups, being twice as high in those aged $60-64$ as those in the $20-29$ age group. The mean age at time of absence was 38.7 years; the mean duration of absence was 23.5 days, and was shown to increase with age. Small regional variations in mean age at absence and mean duration of absence were noted; several ill-defined local factors could account for these variations. The percentage of working days lost through illness $(0.8 \%)$ over the period of the study cannot be compared with United Kingdom figures. Both the labour force survey rate for the period 1987-92, 4.3\% for construction and mining industries ${ }^{2}$ and the Confederation of British Industry rate, 3.1\% for the construction industry ${ }^{22}$ incorporate in their numerators 1 or more days of absence, whereas the present study involves only those days where absences were at least 4 days in duration; additionally, the labour force survey rate is acknowledged as representing a very crude estimate of working days lost, and the Confederation of British Industry cautions that its rate was based on a small sample. Notwithstanding, all the rates represent not only a considerable degree of morbidity but also a considerable loss of productivity in the industry.

Injuries ( $30 \%$ of all absences), infectious disease $(25 \%)$, and musculoskeletal disorders (13\%) accounted for most sickness absence. Cardiovascular disease and chronic obstructive airways disease, together constituted $8 \%$ of absences. The important diagnostic categories were further analysed in age groups which will in many cases suggest specific targeting for health promotion initiatives.

For the person, early retirement on health grounds is not only about the permanent disability which has to be endured; the loss of expected productive years, and the unprepared entry into retirement may have psychological and social consequences. For the industry, it means the loss of experienced workers and the implications of employing and training new personnel. In the present study, the mean annual rate of such retirement was 5.3/1000 workers. The quadratic pattern of these rates over the period of the study could not be explained from available data and was apparently a chance finding. The wide variation in rates mirrors the findings in two organisations in the United Kingdom study. ${ }^{14}$ High annual rates from 1983 to 1988 were due to both a higher number of retirements annually than in other years and a declining study population during that period; the higher number of retirements probably reflects decisions made by workers during the pre-recession and early recession years in the industry to seek early 
retirement on health grounds in their final working years.

The identification of cardiovascular disease, musculoskeletal disorders, chronic obstructive airway disease, and injury as major causes of permanent disabilities leading to early retirement, is a reflection both of the prevalence of the conditions in the general population and the environment and type of work involved in the construction industry. Psychiatric disorder was ranked fifth in the list of most common grounds, corresponding with the low proportion of mental disorders as a reason for sickness absence. The United Kingdom study referred to earlier ${ }^{14}$ showed that psychiatric disorders are one of the most common reasons for early retirement, however, the construction industry was not one of the organisations involved in that study. In the construction and mining industries in the United Kingdom, the category of depression and bad nerves constituted only $2.2 \%$ of all health problems that limit work. ${ }^{2}$

The many potential working years lost due to early retirement on health grounds is an indication of the impact, on both people and the industry, of injuries and illnesses. The impact is greater when retirement takes place at a relatively young age; the study showed that $17 \%$ of those retiring were under the age of 50 years, accounting for $45 \%$ of the potential working years lost.

It is generally accepted that morbidity and mortality associated with many of the disorders leading to sickness absence and premature retirement on health grounds are preventable. The introduction and monitoring of safe work practices, based on Health and Safety at Work legislation in Ireland and voluntary codes of practice, can reduce occupational hazards to health, particularly relative to injury and musculoskeletal disorders. However, effective health promotion, especially in a high risk population, is a crucial element of the complex set of events which can lead to modification of lifestyle, particularly relative to diet, smoking, and lack of exercise which are recognised risk factors in the development of heart disease and many cancers. Chronic obstructive airways disease is important in this context as in some cases it is preventable or its seriousness diminished by changes in lifestyle.

Although this study considered sickness absence and permanent disability in medical diagnostic categories, it is recognised that psychosocial factors at work play a part in, and can be predictive of, sickness absence..$^{23}$ It is further suggested that high rates of sickness absence are often indicators of low morale and incompetent management. ${ }^{24}$ Part of any health promotion programme for industry should be directed at management, particularly emphasising factors contributing to job strain and the desirability of social support at work.

\section{Conclusion}

The study has established patterns of sickness absence and early retirement on health grounds in the Irish construction industry. The appreciable extent of illness and injury leading to both of these have important implications not only for the people in terms of morbidity but for the industry in terms of productivity. Most accidents leading to injury are preventable, and many of the diseases identified can be prevented or modified by suitable changes in lifestyle. The study will provide information that will contribute to the further development of health promotion strategies for workers in the industry.

We thank Pat Ferguson, Administrator of the Construction Federation operatives pension and sick pay scheme, for his advice and assistance at all stages of the research, and Iain Hull, computer analyst, whose expertise enabled data from various sources to be manipulated into a form amenable to analysis. Our thanks go also to Doreen Molloy, Tess Murphy, Joan Kennedy, Martina McGee, and Moirlin McGuire for facilitating the
research. The study was supported by a grant from the European Commission.

1 Leigh JP. Specific illnesses, injuries, and job hazards associated with absenteeism. F Occup Med 1989;31:792-7.

2 Clark S, Elliott R, Osman J. Occupation and sickness absence. In: Occupational Health: the Registrar General's decennial supplement for England and Wales. Office of population censuses and surveys health and safety executive. Series DS no 10. London; The Stationery Office, 1995

3 Osman J, Hodgson J, Hutchings S, et al. Monitoring occupational diseases. In: Occupational Health: the Registrar General's decennial supplement for England and Wales. Office of population censuses and surveys health and safety executive. Series DS no10. London; The Stationery Office, 1995.

4 Burkhart G, Schulte PA, Robinson C, et al. Job tasks, potential exposures, and health risks of laborers employed in the construction industry. Am F Ind Med 1993;24:413-25.

5 Snashall D. Safety and health in the construction industry [editorial]. BMf 1990;301:563-4.

6 Leigh JP, Miller TR. Job-related diseases and occupations within a large workers' compensation data set. Am f Ind within a large workers'

7 Mandell W, Eaton WW, Anthony JC, et al. Alcoholism and occupations: a review and analysis of 104 occupations. Alcohol Clin Exp Res 1992;16:734-46.

8 Arndt V, Rothenbacher D, Brenner H, et al. Older workers in the construction industry: results of a routine health examination and a five year follow up. Occup Environ Med 1996;53:686-91.

9 Coenraads PJ, Nater JP. Sickness and absence from work due to skin diseases in the construction industry. Derm Beruf Umwelt 1984;32:17-21.

10 Coggon D, Inskip H, Winter P, et al. Occupational mortality of men. In: Occupational Health: the Registrar General's decennial supplement for England and Wales. Office of populadecennial supplement for England and Wales. Office of populano10. London; The Stationery Office, 1995.

11 Robinson C, Stern F, Halperin W, et al. Assessment of mortality in the construction industry in the United States, 1984-6. Am fond Med 1995;28:49-70.

12 Reviere R, Schneider S, Woolbright K. Associations between disease and occupation; hypotheses generated
from the National Mortality Followback Survey. Am f Ind Med 1995;27;195-205.

13 Ringen K, Seegal J, Englund A. Safety and health in the construction industry. Annu Rev Public Health 1995;16: $165-88$

14 Poole CJM. Retirement on grounds of ill health: cross sectional survey in six organisations in United Kingdom. BMF 1997;314:929-32.

15 Rothenbacher D, Arndt V, Fraisse E, et al. Early retirement due to permanent disability in relation to smoking in workers in the construction industry. $\mathcal{F}$ Occup Environ Med 1998;40:63-8.

16 World Health Organisation. Health for all in the twenty-first century. Geneva, WHO, 1998.

17 Addley K. Developing programmes to achieve a healthy society: creating healthy workplaces in Northern Ireland. society: creating healthy work
Occup Med 1999;49:325-30.

18 Ebrahim S, Smith GD. Systematic review of randomised controlled trials of multiple risk factor interventions for preventing coronary heart disease. BMF 1997;314:1666-74

19 Bertera RL. The effects of workplace health promotion on absenteeism and employment costs in a large industrial population. Am $\mathcal{F}$ Public Health 1990;80:1101-5.

20 Sorensen G, Stoddard A, Hunt MK, et al. The effects of a health promotion-health protection intervention on behaviour change: the wellworks study. Am $\mathcal{F}$ Public Health 1998; 88: $1685-90$.

21 Martoccio JJ. Age-related differences in employee absenteeism: a meta-analysis. Psychol Ageing 1989;4:409-14.

2 Confederation of British Industry. Missing out: 1998 absence and labour turnover survey. London. Confederation of British Industry, 1998.

23 Niedhammer I, Bugel I, Goldberg M, et al. Psychosocial factors at work and sickness absence in the Gazel cohort: a factors at work and sickness absence in the Gazel cohor :
prospective study. Occup Environ Med 1998;55:735-41.

24 Robertson JS. A modern malaise [editorial]. Public Health 1999;113:155-6. 